\title{
Evaluating the Economic Benefits of Non-Motorized Transport Infrastructure (NMT) for Sustainable Development Case Study: Non-Motorized Transport Pilot Scheme for Kampala City
}

\author{
Joseph Kigozi ${ }^{1}$ \\ ${ }^{1}$ Project Management and Engineering (PROME) Consultants Limited \\ P.O Box 24934, Kampala, Uganda \\ joseph@promeconsult.com
}

\begin{abstract}
Resilient and Smart Non-Motorized transportation systems are vital for sustainable development of cities. The characteristics of the existing transport network in Kampala CBD which is largely dominated by the roads was designed majorly to accommodate the vehicular traffic. Uganda's GDP growth rate has averaged at $4.8 \%$ between 2009 and 2017 the population growth at $2.9 \%$ average based the census years 2002 and 2014. The Ministry of Works and Transport developed and passed the Non-Motorized transport policy in 2012 and currently this policy is at implementation stage. Kampala Capital City Authority in the view of implementing this policy has undertaken a pilot project to establish Non-Motorized Transit corridors such as Namirembe Road and Luwuum Street which will be accessible to only pedestrians and cyclists. Due to migure resources available in developing economies it is absolutely necessary that comprehensive economic evaluation of Pilot infrastructure projects such as NMT is conducted to determine their efficacy before implementation on a broader scale. It is in this spirit that this paper seeks to provide technical assistance to government agencies, consultants, contractors and other stakeholders interested in estimating the economic benefits of NMT Investments.
\end{abstract}

Keywords: Non-motorized transport

\section{Introduction}

Resilient and Smart Non-Motorized transportation systems are vital for sustainable development of cities. The characteristics of the existing transport network in Kampala CBD which is largely dominated by the roads was designed majorly to accommodate the vehicular traffic. Over the years alluded to Uganda's economic growth rate that has averaged at $4.8 \%$ between 2009 and 2017 and a population growth of $2.9 \%$ average based the census years 2002 and 2014 there has been a steady increase in the pressure on the existing roads and this made it close to impossible to access some areas of the city for example the downtown areas using vehicles due to congestion traffic grid lock. It has been observed and proven that city dwellers currently find it more convenient to access these parts of the city on foot. However, it should be primarily noted that the existing infrastructure safe, secure and seamless movement of pedestrians and cases of accidents and theft are common. Suffice it to mention that the carbon emissions in to the atmosphere from various engine types are greatly contributing to environmental pollution hence low quality of life of city dwellers. On the other hand walking and Cycling is an ultimate zero carbon solution to the pollution from motor vehicles that prough the streets of Kampala on a daily basis.

In view of the above, The Ministry of Works and Transport developed and passed the Non-Motorized transport policy in 2012 and currently this policy is at implementation stage. Kampala Capital City Authority (KCCA) in the bid to implement this policy has undertaken a pilot project to establish Non-Motorized Transit corridors such as Namirembe Road and Luwum Street which will be accessible to only pedestrians and cyclists. KCCA has gone further to design other Non- motorized transport schemes that will see a $15 \mathrm{~km}$ path or pedestrians and cyclists along the Kampala-Namanve railway reserve $4 \mathrm{~km}$ of pedestrianised streets within the CBD constructed.

The main objective of this paper is to establish methods which can be employed to evaluate the economic benefits of Non-Motorized transport investments which methods can further be employed to determine the extent to which the implementation of the Non-Motorized transport system can contribute to the sustainable development of cities. This will make it possible to establish measurable economic parameters that can be employed to monitor the performance of NMT projects with a view of continuous improvement of the NMT transport models. It is also intended that this paper provides a basis for city authorities and other interested stake holders to take policy decisions basing on the economic impacts of NMT. 


\section{Target Beneficiaries}

The target beneficiaries for NMT infrastructure development are as detailed in the table 1 below

Table 1: Target Beneficiaries of NMT Infrastructure

\begin{tabular}{|l|l|}
\hline \multicolumn{1}{|c|}{ Beneficiary } & \multicolumn{1}{c|}{ Reason for travel } \\
\hline Pedestrians & Business, School, Recreation, work \\
\hline Cyclists & Business, School, work, Recreation \\
\hline Animal moved Vehicles & Business \\
\hline Skates and Roller blades & Recreation \\
\hline Man Moved vehicles e.g. Carts & Business, work \\
\hline
\end{tabular}

\section{Economic Benefits Of NMT Infrastructure \\ 3.1 Savings on user Costs}

Low user cost and affordability are among the many benefits of walking or bicycling, especially compared to owning and operating a personal vehicle. Reduced travel costs result in a greater portion of pedestrians' and bicyclists' income that can be used for housing, necessities, and other consumer goods. In some cases bicycling may be faster than driving, especially for short trips in dense, urban locations. This creates a benefit in time savings, which can be monetized a number of ways. Businesses and Companies that initiate programs encouraging their employees to commute using nonmotorized transportation may see an improvement in travel time reliability for employees, which could lead to improved productivity. Providing greater access to lower-cost travel options can also have a social equity benefit by increasing access to jobs, opportunities, and community amenities for lower-income populations.

\subsection{Direct Economic Benefits}

Direct economic impacts include money spent that benefits existing urban commercial establishments in sales, produces tax revenues, and creates jobs as a direct result of the new nonmotorized infrastructure (e.g., jobs resulting from the design and construction of nonmotorized infrastructure, bicycle store sales and rentals, and bicycle and pedestrian infrastructuresupported tourism, Improved visibility of displayed merchandise in shops along the NMT corridors).

\subsection{Induced Economic Impacts}

New bicycle and pedestrian infrastructure and programs can have economic impacts beyond sales by bicycle shops or other directly-related businesses (such as walking or bicycling tour companies). Transportation mode can also affect consumer behavior in terms of the frequency with which consumers visit a wider range of businesses and the average amount of money they spend. There are a few potential reasons for consumer behaviour to change with travel mode:

i. Bicyclists and pedestrians who have more disposable income due to reduced travel expenses may be more willing to spend a greater portion of their income on local goods and services.

ii. Bicycle and pedestrian infrastructure may make a commercial corridor more accessible to foot traffic, increasing consumers' browsing opportunities and encouraging more access to local goods and services.

iii. Bicycle and pedestrian infrastructure, along with other forms of traffic calming, may make commercial streets more attractive to visitors and increase visitors' perceptions of safety. 


\subsection{Health Savings}

Increased levels of physical activity that result from use of bicycle and pedestrian infrastructure translate to a reduction in health care costs thus decreasing mortality (rate of death) and morbidity (rate of disease) related to obesity and other health conditions. Low levels of physical activity observed among many Ugandans is a major contributor to rising rates of obesity, diabetes, heart disease, and stroke among other chronic diseases. The above notwithstanding, use of improved bicycling and walking facilities can produce safety benefits related to reduced traffic injuries and fatalities which cuts medical costs and economic losses from injury or death.

\subsection{Environmental Benefits}

Nonmotorized transportation projects also have environmental benefits, such as reduced air pollution and greenhouse gas emissions. These benefits also have an economic dimension. For example, there are human health benefits that result from improved air quality when automobile trips are replaced by nonmotorized trips. Air pollution from transportationrelated emissions is one of the main contributors to poor air quality. Exposure to transportation related pollutants is associated with several adverse health effects, such as premature mortality, cardiac symptoms, exacerbation of asthma symptoms, diminished lung function, and increased hospitalization. Improved air quality can also have other economic benefits. For example, improved visual air quality can benefit local tourist-related businesses such as tour guide services and sale of crafts and antiques. There are also economic benefits from reduced greenhouse gas emissions, with possible health implications, they can be diffuse and difficult to measure at a local scale.

\section{Estimation Of Economic Benefits Of Nmt Infrastructure}

Economic impact evaluation is strengthened by a before and after analysis, with a detailed baseline analysis being carried out before the investment is out in place. Base line analysis involves collecting information about every type of impact foreseen before the investment. The base line studies should also include perception studies where opinions are gathered from the intended project beneficiaries regarding the proposed infrastructure in regards to cost of travel, accessibility, safety and comfort.

The Economic Benefits detailed in section 3 can be measured with reasonable effectiveness and at different scales. The data to facilitate the measuring of these benefits can be acquired from Field surveys and observation, tax receipts, sales receipts, interviews, Hospital records among others. The data collected can then be analysed by employing economic models to study the impacts of the investments.

\subsection{Estimation of Savings on User Costs}

The economic benefits to users may be measured through user surveys of their travel behaviours and costs. Differences in travel costs can then be generalized based on documented changes in mode change from private vehicles or transit to nonmotorized transportation modes. This could be determined by conducting origin destination surveys where data regarding (i) how the people have travelled to the locality, frequency of visits, purpose of visits and the costs incurred in making the visit(spending patterns) using motorized transport means can be determined and compared with an approximate cost of making the same trips with NMT modes

During the preparation of this paper an assessment of the costs of transport per kilometer using motorized modes within the Central business district was conducted and the observations are shown in the table below. 
Table 2: Estimated Cost of Motorized Transport means in Kampala.

\begin{tabular}{|l|c|c|}
\hline $\begin{array}{l}\text { Mode of } \\
\text { transportation }\end{array}$ & $\begin{array}{c}\text { Average Estimated Cost per } \\
\text { Km (UGX) }\end{array}$ & $\begin{array}{c}\text { Average Estimated } \\
\text { Cost per Km (USD) }\end{array}$ \\
\hline 14-seater Taxi & 400 & 0.108 \\
\hline $\begin{array}{l}\text { Boda Boda } \\
\text { (motorcycle) }\end{array}$ & 1500 & 0.407 \\
\hline Private car & 1000 & 0.271 \\
\hline Private Taxi & 2000 & 0.542 \\
\hline
\end{tabular}

This means that an individual travelling by a 14-Seater Taxi from Namanve to Kampala CBD a distance of $15 \mathrm{~km}$ for work spends an average of UGX 12000 or USD 3.3 per day to travel to and from work. If the individual shifts to a bicycle and rides along the NMT corridor envisaged between Namanve and the CBD he will save and average of USD 1200 per year.

From the traffic surveys conducted during the Detailed Design of Non-Motorised Transport Schemes for Kampala City, there are a total of current 29,160 NMT users in the Kampala CBD, assuming each user travels an average $15 \mathrm{~km}$ per day there will be a total saving of USD 34,992,000 per year. This value is expected to be even much higher because of the expected mode shift from Private cars, boda bodas and private taxis.

\subsection{Estimation of Direct Economic Impacts}

Direct benefits to bicycle- or pedestrian-related businesses can be measured through business surveys, tax receipts and remittances and a count of the number and size of such businesses in a community or geographic area. However, this type of analysis requires baseline data from before the investment is put in place. Data on the number of people (through pedestrian counts) visiting a mall or shopping centres within the NMT corridor before the NMT infrastructure is put in place and after gives an indication of the potential increase in sales for the businesses in that shopping centre due to the attraction of new visitors. According to Cliffton et al Cyclists tend to spend less per visit but make more visits than visitors traveling by other means. This school of thought also applies to pedestrians. The attraction of new visitors can also be derived from the change in traffic characteristics along the roads leading to the NMT Zone. The Tax remittances of the different businesses which can be obtained from tax bodies such as URA for the Uganda Case also give an indication on whether the NMT infrastructure is contributing to the Growth of businesses or not. Development of new businesses resulting from the NMT infrastructure can be monitored using data from Business registration authorities like the Uganda Registration Services Bureau (URSB). Business Surveys include interviews with business owners to obtain data on business performance in terms of turnover before and after the commissioning of new NMT infrastructure. This data should however remain strictly confidential.

Luwum street which forms part of the NMT pilot corridors thus far completed has seen a significant rise in the number if businesses operating along its corridor. Informal discussions with the business owners indicated that the number potential buyers that visit the shops has risen resulting into growth of sales. This is also attributed to the increased sense of security and comfort for the shoppers. 


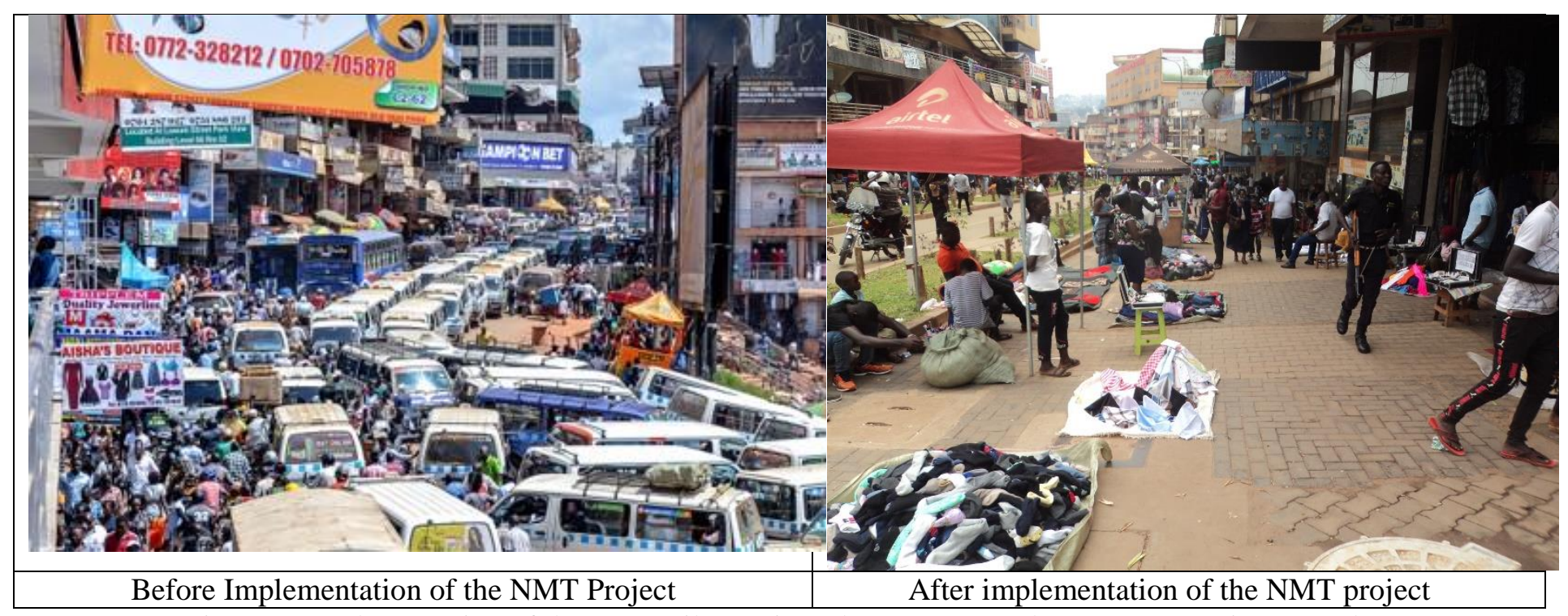

Figure 1: Implementation of the NMT Pilot project along Duster and Luwum Street in Kampala

\subsection{Estimation of Induced Economic Impacts}

Induced Economic impacts can be determined though consumer surveys related to their travel and behaviour. Mode shifts have to be considered in this survey.

Substantial data is necessary for both mode shares and consumer behaviour before and after the project is implemented.

The induced Economic impacts include;

i. Improved property value which can be tracked by acquiring data on the changes in property prices, vacancy rates, rental tax Remittance and Rental income for building landlords before and after the commissioning of NMT infrastructure. Comparison between the changes in property prices and commercial rents in the Vicinity of NMT infrastructure will give an indication on the impact of the NMT investment on property value. It is advisable to commence data collection some time before the NMT investment is put in place because property prices and rents can start adjusting in anticipation of major transport infrastructure being put in place.

ii. Changes in the levels of Un Employment.

Accruing to the growth in businesses there are likely changes envisaged in the level of unemployment for some occupational groups. Indication regarding changes in unemployment can be given by Tax income foregone, the cost to provide benefits to the unemployed, cost to provide family and individual credit facilities, level of exportation of labour exported by external recruitment agencies. Changes in the levels of Crime in the area as analysed from the police records can is also a good indicator in the Changes of unemployment.

iii. Development of the Cycling industry

Establishment of NMT infrastructure will lead to an increase in the number of Cyclists which will increase the sales of bikes, bike parts as well as the market for bike repair and maintenance services. As such there will be newly created jobs for bike designers, trainers and mechanics this will in turn lead to growth of the cycling industry which will in turn add to the Country's GDP. Evaluation of this impact will require primary research to be carried out in the levels of sales and employment in the cycling industry before and after the implementation of infrastructure 
iv. Reduction in travel times resulting in to Improved productivity

This aspect can be analysed by considering the time saved when using NMT infrastructure to make trips and the value of that time saved. For example, if a food delivery service provider is to use a car to make a trip of $1 \mathrm{~km}$ it may take him say 14 minutes. If the same service provider used a bicycle it makes take say 7 minutes thus a saving of 7 minutes. This means in the saved 7 minutes the service provider can make an extra delivery thus extra income. This extra money obtained is the economic value of the time saving. Data on the time saved can be obtained from journey time surveys on selected trips within the NMT zone of influence before and after commissioning the infrastructure and thereafter attaching a cost to this time saved.

\subsection{Estimation of Health Impacts/Benefits}

It is apparent that cycling and walking has potential to improve health for both individuals and society at large. The Change in the prevalence of type 2 diabetes in the catchment area of the NMT infrastructure is a worthy indicator of the health impacts of Cycling and walking. The health benefits can be quantified by the cost saving realised as a result of the reduction in the prevalence of type 2 diabetes in terms of cost of drugs and inpatient services. Data on the prevalence of diabetes can be collected from health facilities within the zone of influence of the NMT infrastructure before and after the commissioning of the infrastructure. It is advisable that a minimum of three data points are taken at the same time of the year to avert seasonal effects.

Alternatively, Health benefits can be determined by using tools such as the Health Economic Assessment Tool (HEAT) developed by the World Health Organization. HEAT is designed to enable users to conduct economic assessments of the health impacts of walking and cycling. HEAT estimates the value of reduced motility that results from specified amounts of walking and cycling. HEAT can be used for assessments such as;

(i) Assessment of current or past levels of cycling and walking

(ii) Assessment of changes overtime i.e before and after comparisons

(iii) Evaluation of new or existing projects

Using this tool comprises of 5 major steps; (i) defining the assessment, (ii) providing input data (iii) providing information for data adjustments (iv) review of calculation parameters (v) results.

The Integrated Transport and Health Impacts Model (ITHIM) developed by James Woodcock. is a comprehensive tool that can estimate the hypothetical health effects of transportation mode shifts through changes in physical activity, air pollution and injuries.

\subsection{Estimation of Environmental and Social Benefits}

The mode shift from motorized transport to Non-motorized transport contributes to the reduction in air pollution, reduced greenhouse gas emissions, noise, road deaths and injuries resulting from motor accidents, congestion and social isolation (Hart and Parkhurst,2011). Noise pollution maybe associated with elevated stress levels. Feitsberaad (2010) argues that a $10 \%$ increase in cycling is expected to decrease noise pollution by $2 \%$.

The Nitrogen dioxide contained in vehicle emissions increases the symptoms of the people suffering from respiratory and heart disease. A study that was conducted in Netherlands on the environmental impacts of cycling revealed that a $10 \%$ increase in Cycling caused a decrease in carbon dioxide emissions from cars by $7 \%$. The same study also suggests that the improved flow of traffic contributes to the decrease in carbon dioxide emissions of heavy trucks to a tune of about $4 \%$.

The Logic of estimating environmental benefits is that provision of NMT infrastructure is that creates a switch in transport modes reducing congestion and improving the flow of motorized traffic due to reduction in traffic jam. The improvement in air quality produces a reduction in pollution induced respiratory incidents such as asthma thus a reduction in premature deaths. 
The effect of the change in air pollution levels before and after the commissioning of NMT investments can be measured using meters such as Nitrogen dioxide and Carbon dioxide gas detectors which can measure the concentration of nitrogen dioxide and carbon dioxide and particulates such as PM10 and PM 2.5.

The change in Pollution levels can also be measured by analysis of the change in the prevalence and treatment of asthma. Asthma is a chronic condition which can be brought on and exacerbated by ambient air pollution. Asthma is a good indicator because It is wide spread and well documented and responds in a short time to changes in air quality.

In line with the above measurement of the environmental impact of NMT infrastructure will require data on asthma episodes recorded and treated before and after the investment. This data can be supplemented by interviews with asthma patients with the NMT infrastructure zone of influence to determine the frequency of the occurrence of the asthma attacks before and after the investment and the cost of treatment of each asthma attack. The change in the frequency of occurrence of these attacks gives an indication of the cost saving accrued due to the NMT infrastructure. This data needs to be collected at different times of the year before the investment and several years after the investment.

\section{Cumulative Economic Impacts}

The Cumulative economic impacts resulting from amalgamation of all the benefits can be estimated using Economic Analysis Models such as Regional Economic Model,inc (REMI), IMPLAN and Transportation Economic Development Impact System (TREDIS). These Models are employed to conduct pre- project Cost benefit analysis as well as post project evaluation.

Once all costs and benefits are monetized, the ratio of benefits to costs are calculated and evaluated to determine feasibility and desirability.

\section{Scales of Observation}

It is of paramount importance the scales of observation had are appropriately taken into consideration when evaluating economic impacts of NMT Investments. Each individual scale of Observation has its benefits and drawbacks and may or less be appropriate for different projects. The Scales of observation are;

i) Micro Scale

This includes surveys on individual business owners such as shops and restaurants that utilize NMT investments.

ii) Meso Scale

This is an intermediate scale between the scale of individual business owners and a larger scale of a city or county.

iii) Macro Scale

This is usually Country wide or state-wide. The economic models such as REMI, IMPLAN and TREDIS are more suited for this kind of analysis.

\section{Observations and Conclusions}

- There exists a wide variety of options that can be employed to measure and assess the economic benefits of NMT infrastructure. Some of the methods and models are still undergoing development and calibration therefore researchers should always first ascertain the goals of therefore analysis before using any given tool or model for analysis.

- Each economic analysis tool has unique advantages as well as disadvantages that rotate around Cost, Complexity, Data requirements, availability of documentation among others. It is advisable that due to the time taken for changes in transport infrastructure to feed through the economic sphere it is recommended that the evaluation after the commissioning of the NMT infrastructure take 2-3 years. 
- The Ministry of Works non-motorized transport policy states that "The Government will commission a study review on fiscal profile and economic benefits of bicycle use to inform the case for possible reduction or elimination of the duties and taxes currently imposed on bicycles." It further states that "appropriate research studies shall be arranged to gain more information and understanding concerning NMT and its social and economic benefits". The methods suggested in this paper crucial and good starting point in conducting these intended studies.

\section{References}

[1] Heidi, G.-P. (2010). Estimating Economic Impacts of Pedestrian, Bicycle and Road Infrastructure.

[2] Iganga Foundation. (2014). Smart Moving Kampala, Design of NMT Zone in Namirembe and Luwum Street.

[3] Interface for cycling expertise. (2000). The signifcance of non motorized transport for developing countries.

[4] Komanoff, C., \& Roelofs, C. (1993). The Environmental Benefits of Cycling and walking.

[5] Litman, T. (2009). Quantifying the benefits of Non Motorized Transportation for achieving mobility management objectives. Victoria Transport Policy Institute.

[6] Litman, T. (2019). Evaluating Active Transport Benefits and Costs. Victoria Transport Policy Institute.

[7] Mat, Y., R, I., \& R, A. (2011). The Use of Non-Motorized fpr sustainable transportation in Malaysia. Elsevier.

[8] Ministry of Works and Transport. (2012). Non-Motorized Transport Policy.

[9] NZ Transport Agency. (2009). Pedestrian Planning and Design Guide.

[10]Rahul, T. M., \& Ashish, V. (2012). Economic Impact of non-motorized transportation in indian cities. Bangalore: Elsevier.

[11]Todd, L. (2009). Transportation Cost and Benefit Analysis Guidebook.

[12] World Health Organization. (2014). Health economic assesment tool (HEAT). Retrieved November 2019, [Online].Available:http://www.heatwalkingcycling.org/htttp://heatwalkingcycling.org/index.php?pg=cycling \&act $=$ more 1

[13] World Health Organization. (2014). Health Economic assesment tools for walking and for cycling. Retrieved September 2019, [Online]. Available:

http://www.heatwalkingcycling.org//heatwalkingcycling.org/index.php?pg+cycling\&act=more1 